\title{
BIOSECURE - A SPATIALLY EXPLICIT MODEL FOR ASSESSING RISK ASSOCIATION WITH ALIEN ORGANISMS IN NEW ZEALAND INDIGENOUS ECOSYSTEMS
}

\author{
G.M. BARKER ${ }^{1}$, C. HUNTER ${ }^{1}$, A. STEPHENS ${ }^{1}$, D. RUTLEDGE ${ }^{1}$, \\ R. HARRIS ${ }^{2}$ and M.-C. LARIVIERE ${ }^{3}$ \\ ${ }^{1}$ Landcare Research, Private Bag 3127 Hamilton \\ ${ }^{2}$ Landcare Research, Private Bag 6 Nelson \\ ${ }^{3}$ Landcare Research, Private 92170 Auckland \\ Corresponding author: barkerg@landcare.cri.nz
}

\begin{abstract}
BIOSECURE is a decision-support tool for management of biosecurity risks to New Zealand's indigenous ecosystems. Structured with an inquiry menu on a specifically designed Internet web browser linked to database and GIS software, BIOSECURE enables identification and analysis of risks associated with source areas, pathways of imported goods and particular organisms. In addition to the traditional comparisons of climates, BIOSECURE uses information on resources (e.g. host plants for herbivores), ecosystem nutrient status (soil nitrogen and phosphorus) and biotic assemblage (as index of release from competitors and enemies) to define and quantitatively contrast the species' native niche and potential invasive niche. BIOSECURE then refines these estimates of the potential invasive niche space within New Zealand by analyses of the spatial configuration of indigenous ecosystems (including proximity and connectedness to ports) and the degree of anthropogenic disturbance in those ecosystems (including the prior establishment of the species' natural hosts). BIOSECURE has application in developing Import Health Standards to support New Zealand's sanitary measures, and in evaluating purposeful introductions under the HSNO Act. Additionally, BIOSECURE provides for generic analysis of biosecurity risks in New Zealand's indigenous ecosystems to guide policy and operational activities in border control, internal surveillance and pest management.
\end{abstract}

\section{FULLER'S ROSE WEEVIL RESPONSES TO LEMON VOLATILES}

\author{
D.M. SUCKLING, J.M. DALY, J.K. HACKETT and A.R. GIBB
}

\author{
HortResearch, PO Box 51, Lincoln \\ Corresponding author: msuckling@hortresearch.co.nz
}

Fuller's rose weevil (Asynonychus cervinus) is a market access pest of export kiwifruit and citrus. Laboratory choice assays were designed to identify aspects of the insect's behaviour that might be exploited as the basis for possible future control tactics. Weevils were significantly attracted to fresh lemon foliage compared to fresh cut lemon foliage. Dried cut or uncut lemon foliage was least attractive. Choice tests indicated that commercial lemon leaf oil was significantly more attractive than untreated controls. Coupled gas chromatography-electrophysiological recording of weevil antennal responses to the lemon oil indicated that weevils detected at least eight constituent monoterpene components of the oil. Further work is needed to understand the potential for developing pest management of Fuller's rose weevil using these cues, and exploration of the mechanisms involved will be needed to fully develop this potential. 